\title{
Cyberbullying escenario de la violencia en el contexto educativo
}

\author{
Dorantes Carrión, Jeysira Jacqueline \\ Universidad Veracruzana, México \\ jeysira@hotmail.com
}

Resumen - El cyberbullying es una manifestación de la violencia en las redes sociales, tema del presente estudio, el cual se desarrolló en la Facultad de Pedagogía del Sistema de Enseñanza Abierta (SEA) de la Universidad Veracruzana (UV). Se apoyó en la teoría de las representaciones sociales, de Moscovici (1961), y se emplearon dos técnicas de investigación: 1) asociación libre de palabras y 2) dibujo (Abric, 1994). Su análisis se realizó con el software IRaMuTeQ, mediante el cual se demuestra que el cyberbullying es "violencia" y "acoso" por Facebook.

Palabras Clave: Cyberbullying; Violencia; Acoso; Facebook;

Abstract - Cyberbullying is an expression of violence in social networks, theme of the present study, which was made at the School of Pedagogy of the Open Teaching System (SEA, in Spanish) of the Universidad Veracruzana (UV). It was based on Moscovici's theory of social representations and the research techniques used were: free association of words and drawing
(Abric, 1994). The analysis was made using IRaMuTeQ, this has help to show that cyberbullying is a common way of "violence" and "harassment" in Facebook.

Keywords: Cyberbullying; Violence; Harassment; Facebook;

\section{INTRODUCCIÓN}

Este documento, intitulado "Cyberbullying: escenario de la violencia en el contexto educativo", presenta los resultados de una investigación desarrollada en la Facultad de Pedagogía del Sistema de Enseñanza Abierta (SEA) de la Universidad Veracruzana (UV), con estudiantes del seminario "Prácticas de docencia". Se apoyó en la teoría de las representaciones sociales, de Moscovici (1961), y en autores que sustentan la violencia y el cyberbullying: Furlán, Pasillas, Spitzer y Gómez (2010); Leoni 
(2012); Castro (2012); Morales, Serrano, Miranda y Santos (2014); Casillas, Ramírez y Ortiz (2014); Molina y Vecina (2015); OrtegaRuiz y Zych (2016); Dorantes, Oliva y Rivera (2017); Dorantes, Lagunes, Oliva y Rivera (2019); Dorantes (2016 y 2017), entre otros; para explicar el uso inadecuado de las tecnologías de la información y comunicación (TIC) y las redes sociales con el objeto de generar daño entre estudiantes universitarios por medio de dispositivos móviles conectados a Internet; es decir, el cyberbullying.

En el estudio se emplearon dos técnicas de investigación: 1) asociación libre de palabras y 2) dibujo o soporte gráfico (Abric, 1994). El análisis de los datos se realizó con el software IRaMuTeQ (Molina-Neira, 2017). Los resultados de la asociación libre arrojan, en una nube de palabras, la representación social construida y compartida del cyberbullying: "violencia" y "acoso"; y, en el árbol de similitud, que en Facebook e Internet se "agrede", "hostiga", "humilla", "burla", "exhibe", "ataca" y "maltrata". Por su parte, el dibujo demuestra que el cyberbull- ying genera problemas, depresión, daño psicológico e, incluso, el suicidio. Así, la representación social del cyberbullying es el ataque virtual en redes sociales.

Como referente teórico, se utilizó la teoría de las representaciones sociales (TRS) (Moscovici, 1979), cuyo origen es la psicología social y la sociología del conocimiento (Banchs, 2000). La representación social es "una organización de imágenes y de lenguaje porque recorta y simboliza actos y situaciones que se convierten en comunes" (Moscovici, 1979, p. 16). Trata de captar la realidad a partir de la mirada de los individuos insertos en un contexto social y específico, como el contexto de la Universidad Veracruzana (UV) para la presente investigación.

En este trabajo se buscó conocer cuáles son las representaciones sociales del cyberbullying $\mathrm{y}$, a partir de ellas, poder dar cuenta de la realidad. Cabe señalar que en una representación social el individuo ordena, organiza y jerarquiza el contenido de la representación, le asigna un valor de importancia y atribuye un significado a partir de 
un contenido que ha sido organizado y jerarquizado (Flament, 1994, p. 37) por un grupo, en este caso de estudiantes universitarios.

Por su parte, el cyberbullying es una nueva forma de violencia en las redes sociales. Impacta al $10 \%$ de los universitarios, quienes han experimentado sus efectos negativos por medio de plataformas, foros de estudiantes, blogs y Hatebook (Dorantes, 2017, p. 174); donde se suben contenidos dañinos (fotos 0 videos de contenido sexual o pornográfico, comentarios destructivos, etc.) en forma viral, con el fin de destruir, humillar, denigrar, acosar, extorsionar, amenazar, exhibir y violentar.

Debe señalarse que la violencia en redes sociales se manifiesta de diversas maneras: "spam, spoofing $y$ pharming; el acoso, el bombing $o$ el bombardeo; los virus, los proveedores de servicios de correo electrónico de la red" (Junta de Castilla y León, 2010, pp. 53-54). El cyberbullying se suma el sexting, sextorsión, grooming, pornografía infantil, trata de personas, lenocinio, turismo sexual, pedofilia, amenazas, acoso y difamación.
A pesar de la aparente familiaridad de los jóvenes con la tecnología y la sensación experimentada de control o inocuidad, la red se desarrolla cualitativa o cuantitativamente en direcciones no siempre deseables, y a una velocidad que hace difícil establecer medidas mitigadoras de los posibles impactos perjudiciales sobre el crecimiento emocional y personal. Muchas veces los usuarios dañan o se exponen a riesgos en las redes sociales ante la interacción con desconocidos, o frente al acceso a contenidos inadecuados, que incitan al "desarrollo de comportamientos disfuncionales de convivencia" (Junta de Castilla y León, 2010, pp. 6-9).

Además, el cyberbullying no es específico de un grupo etario, sino que afecta a estudiantes de todas las edades y de los diversos niveles educativos. En un estudio previo (Dorantes, 2017), se demostró que los estudiantes universitarios experimentan diversos tipos de violencia: verbal (17.6\%), docente $(15.5 \%$,$) física (12.9 \%)$, psicológica o emocional (12.3\%), de género $(11.6 \%)$, económica $(10.2 \%)$, cyberbullying $(10.0 \%)$, sexual $(8.7 \%)$; $y$, 
en menor medida, escolar (0.6\%), administrativa $(0.4 \%)$ y familiar $(0.2 \%)$ (p. 170). Este panorama refleja que se experimentan violencias entrecruzadas, pero también se suma la generada en redes sociales; la violencia ha cambiado al escenario virtual, donde se potencializa de manera indirecta, invisible, anónima; y genera daños muchas veces irreversibles.

La labor como académicos e investigadores universitarios es conocer el impacto de este fenómeno y concientizar sobre los problemas que genera; incitar al buen uso de las tecnologías de la información y comunicación (TIC), y prevenir consecuencias catastróficas, como el suicidio. Es posible prever daños irreversibles en nuestros estudiantes, cambiar el presente y asegurar un futuro armonioso.

Por ello, es importante trabajar y concientizar; plantear la posibilidad de optimizar las TIC, y fortalecer las virtudes y generosidades que nos ofrecen, como descargar un libro, acceder a museos de otros países de manera gratuita, estar en contacto con el arte, la música y nuevos descubrimientos. También debemos fortalecer las relaciones humanas; inculcar el respeto. Todos, sin distinción de género, debemos pregonar $y$ fomentar una cultura de la paz.

\section{DESARROLLO}

Se seleccionó el abordaje metodológico cualitativo, apoyado en dos técnicas de investigación: 1) asociación libre de palabras y 2) dibujo o soporte gráfico (Abric, 1994), que permiten estudiar y comprender las representaciones sociales.

La asociación libre posibilita tener una producción verbal y reducir la dificultad o los límites de la expresión discursiva. Consiste en pedir al sujeto que produzca todos los términos, expresiones o adjetivos que se le presenten al espiritu, a partir de un término inductor (en este caso, cyberbullying). El carácter espontáneo permite el acceso a los núcleos figurativos de la representación. Es una técnica capital para recolectar los elementos constitutivos del contenido de la representación, lo que explica su éxito actual y su utilización sistemática en numerosas investigaciones (Abric, 1994, $p$. 60). 
Esta técnica es de rápida aplicación para su control. En la investigación, se asignó un número de folio a tarjetas entregadas a los estudiantes; esto permitió mantener un orden. Se efectuó un análisis a nivel léxico (tipo de léxico, dispersión, coocurrencias, relaciones verbos-adjetivos), complementado por el análisis de las categorías temáticas, con informaciones importantes acerca de la naturaleza del contenido de la representación: el cyberbullying (Abric, 1994, p. 61).

Después de entregar una tarjeta blanca al estudiante, se solicitó que escribiera todas las palabras que le vinieran a la mente ante la palabra cyberbullying. Posteriormente, se le pidió que numerara las palabras del 1 al 5 , conforme a su importancia. Una vez finalizada esta actividad, se le solicitó dar vuelta a la tarjeta para agregar datos relacionados con la edad, sexo, semestre y facultad.

Por su parte, el dibujo o soporte gráfico permite la verbalización de los sujetos a partir de los dibujos $\mathrm{y}$, posteriormente, el análisis de los elementos constituyentes de la producción gráfica. Posibilita poner en evidencia los elementos organizadores de la producción, es decir, la significación central de la representación social producida. "Los dibujos son un conjunto estructurado y organizado alrededor de elementos o significaciones centrales que permiten identificar el contenido y formular hipótesis sobre los elementos centrales de la representación" (Abric, 1994, p. 58).

En la investigación, consistió en entregar una hoja blanca tamaño carta, colores, plumones y lápices a cada estudiante. Se solicitó que dibujara lo que considerara cyberbullying. Posteriormente, se le pidió dar vuelta a la hoja para explicar con sus propias palabras lo dibujado; además de agregar datos referentes a su edad, sexo, semestre y facultad, con el objetivo de mantener un control de los datos. Cada dibujo comprende un código, que incluye número de folio, sexo, edad, facultad y semestre; por ejemplo: (1-Mas, 28-FP-6 ${ }^{\circ}$, con la finalidad de mantener el anonimato.

La población de estudio estuvo integrada por 10 estudiantes de la Facultad de Pedagogía de la UV, del SEA, que asistieron al semina- 
rio "Prácticas de docencia" en el 2019 (Tabla 1). Se tuvo una participación de tres hombres y siete mujeres, de entre 20 y 32 años; cursaban los semestres $4 .^{\circ}, 6 .^{\circ}$ y $8 .^{\circ}$, debido a que la Facultad trabaja con el Modelo Educativo Integral y Flexible (MEIF).

En la Tabla 2 se presenta el concentrado de la técnica de asociación libre.

Posteriormente, se procedió al empleo del software especializado para el análisis de datos cualitativos, denominado IRaMuTeQ (Interfaz de $R$ para el Análisis Multidimensional de los Textos y
Cuestionarios)

(Molina-Neira, 2017), que se encarga de efectuar un análisis a nivel léxico (tipo de léxico, dispersión, coocurrencias, relaciones verbos - adjetivos), complementado por el análisis de las categorías temáticas.

Posteriormente, la información obtenida de la asociación libre se traslada a un bloc de notas plano que integra el corpus de la información, y se pasa a un formato txt, que es leído por el software, obteniendo una organización y jerarquía de las palabras evocadas, mismas que están concatenadas y organizadas de acuerdo con la importancia del objeto representado. Así, el resultado es una nube de palabras

Tabla 1. Estudiantes de la Facultad de Pedagogía SEA-UV-2019.

\begin{tabular}{|c|cccc|}
\hline Participante & Carrera & Semestre & Edad & Sexo \\
\hline 1 & Pedagogía & $6 .^{\circ}$ & 20 & Femenino \\
\hline 2 & Pedagogía & $6 .^{\circ}$ & 21 & Masculino \\
\hline 2 & Pedagogía & $6 .^{\circ}$ & 21 & Femenino \\
\hline 4 & Pedagogía & $6 .^{\circ}$ & 25 & Femenino \\
\hline 5 & Pedagogía & $6 .^{\circ}$ & 28 & Masculino \\
\hline 6 & Pedagogía & $8 .^{\circ}$ & 25 & Femenino \\
\hline 7 & Pedagogía & $6 .^{\circ}$ & 25 & Femenino \\
\hline 8 & Pedagogía & $6 .^{\circ}$ & 32 & Femenino \\
\hline 9 & Pedagogía & $4 .^{\circ}$ & 23 & Masculino \\
10 & Pedagogía & $4 .^{\circ}$ & 23 & Femenino \\
\hline
\end{tabular}

Fuente: Elaboración propia. 
Tabla 2. Asociación libre de palabras sobre el cyberbullying.

\begin{tabular}{|c|c|c|c|c|}
\hline Informante 1 & Informante 2 & Informante 3 & Informante 4 & Informante 5 \\
\hline $\begin{array}{l}\text { Suicidio } \\
\text { Depresión } \\
\text { Violencia } \\
\text { Acoso } \\
\text { Extorsión } \\
\text { Problemas familiares } \\
\text { Extorsión } \\
\text { Depresión } \\
\text { Suicidio } \\
\text { Violencia } \\
\text { Mal uso del Internet } \\
\text { Rechazo } \\
\text { Burla }\end{array}$ & $\begin{array}{l}\text { Violencia } \\
\text { Acoso } \\
\text { Depresión } \\
\text { Burlas } \\
\text { Indignación } \\
\text { Facebook } \\
\text { Enojo } \\
\text { Exhibicionismo } \\
\text { Llanto } \\
\text { Traumas } \\
\text { Inseguridad }\end{array}$ & $\begin{array}{l}\text { Violencia } \\
\text { Agresión } \\
\text { Humillación } \\
\text { Ridiculizar } \\
\text { Hostigar } \\
\text { Ofender } \\
\text { Difamar } \\
\text { Anonimato } \\
\text { Burlarse } \\
\text { Exhibir } \\
\text { Venganza } \\
\text { Tristeza } \\
\text { Fotos } \\
\text { Frases hirientes } \\
\text { Molestar } \\
\text { Hostigar } \\
\text { Disfrutar } \\
\text { Agresor } \\
\text { Victima } \\
\text { Participar } \\
\text { Callar }\end{array}$ & $\begin{array}{l}\text { Crimen } \\
\text { Normalizado } \\
\text { Enojo } \\
\text { Frustración } \\
\text { Abuso } \\
\text { Molestia } \\
\text { Impotencia } \\
\text { Tristeza } \\
\text { Delito } \\
\text { Violencia Física } \\
\text { Violencia psicológica } \\
\text { Crimen } \\
\text { Juego } \\
\text { Diversión } \\
\text { Representaciones } \\
\text { juveniles } \\
\text { Crítica } \\
\text { Mentira } \\
\text { Juego }\end{array}$ & $\begin{array}{l}\text { Discriminación } \\
\text { Acoso } \\
\text { Agresión } \\
\text { Manipulación } \\
\text { Violencia } \\
\text { Poca privacidad } \\
\text { Cobardía } \\
\text { Maltratos } \\
\text { Intolerancia } \\
\text { Inseguridad } \\
\text { Delincuencia } \\
\text { Desorden } \\
\text { Problemas } \\
\text { Daño Psicológico } \\
\text { Seguridad virtual } \\
\text { Participación activa } \\
\text { Participación no activa }\end{array}$ \\
\hline Informante 6 & Informante 7 & Informante 8 & Informante 9 & Informante 10 \\
\hline $\begin{array}{l}\text { Violencia } \\
\text { Internet } \\
\text { Sufrimiento } \\
\text { Redes sociales } \\
\text { Problemas } \\
\text { Abuso } \\
\text { Maltrato } \\
\text { Acoso } \\
\text { Sufrimiento } \\
\text { Problemas } \\
\text { Internet } \\
\text { Agresión } \\
\text { Burla } \\
\text { Diversión } \\
\text { Humillación }\end{array}$ & $\begin{array}{l}\text { Sin valores } \\
\text { Computadoras } \\
\text { Sociedad } \\
\text { Chavos } \\
\text { Escuelas } \\
\text { Burlarse } \\
\text { Celulares } \\
\text { Facebook } \\
\text { WhatsApp } \\
\text { Maldad } \\
\text { Irrespetuoso } \\
\text { Perverso } \\
\text { You Tube } \\
\text { Instagram }\end{array}$ & $\begin{array}{l}\text { Acoso } \\
\text { Violencia } \\
\text { Red } \\
\text { Computadora } \\
\text { Internet } \\
\text { Burla } \\
\text { Fotos } \\
\text { Videos } \\
\text { Daño Psicológico } \\
\text { Trauma } \\
\text { Meme } \\
\text { Ataque } \\
\text { Compartir } \\
\text { Celular } \\
\text { Tablet } \\
\text { Escuela } \\
\text { Casa } \\
\text { Viral } \\
\text { Compañeros } \\
\text { Amigos } \\
\text { Familia } \\
\text { Denuncia } \\
\text { Castigo } \\
\text { Social } \\
\text { Manipulable } \\
\text { Teclado } \\
\text { Perfiles falsos } \\
\text { Mentiras } \\
\text { Chismes }\end{array}$ & $\begin{array}{l}\text { Abuso } \\
\text { Acoso } \\
\text { Agresión } \\
\text { Molestia } \\
\text { Integridad } \\
\text { Autoestima } \\
\text { Redes Sociales } \\
\text { Facebook } \\
\text { Instagram } \\
\text { WhatsApp } \\
\text { Memes } \\
\text { Discriminación } \\
\text { Humillación } \\
\text { Falsedad } \\
\text { Engaño } \\
\text { Depresión } \\
\text { Victima } \\
\text { Ataque } \\
\text { Educación } \\
\text { Valores } \\
\text { Groserias } \\
\text { Sexo } \\
\text { Fotografias } \\
\text { Chismes } \\
\text { Problemas } \\
\text { Ofensas } \\
\text { Género } \\
\text { Delito } \\
\text { Escuela } \\
\text { Trabajo } \\
\text { Sociedad } \\
\text { Suicidio } \\
\text { Difamar } \\
\text { Hostigar } \\
\text { Burlas } \\
\text { Vulnerable } \\
\text { Indignación } \\
\text { Desprecio } \\
\text { Odio } \\
\text { Indiferencia }\end{array}$ & $\begin{array}{l}\text { Internet } \\
\text { Comentarios } \\
\text { Redes Sociales } \\
\text { Mal uso de palabras } \\
\text { Acoso } \\
\text { Risas } \\
\text { Denigración } \\
\text { Groserias } \\
\text { Ofensas } \\
\text { Sensibilidad } \\
\text { Falsedad } \\
\text { Privacidad } \\
\text { Divulgación } \\
\text { Engaño } \\
\text { Baja autoestima } \\
\text { Levantar falsos } \\
\text { Imágenes obsenas }\end{array}$ \\
\hline
\end{tabular}

Fuente: Elaboración propia. 
donde se observan las más destacadas, pero también la representación social dominante sobre el cyberbullying (Figura 1).

Figura 1. Nube de palabras 1.

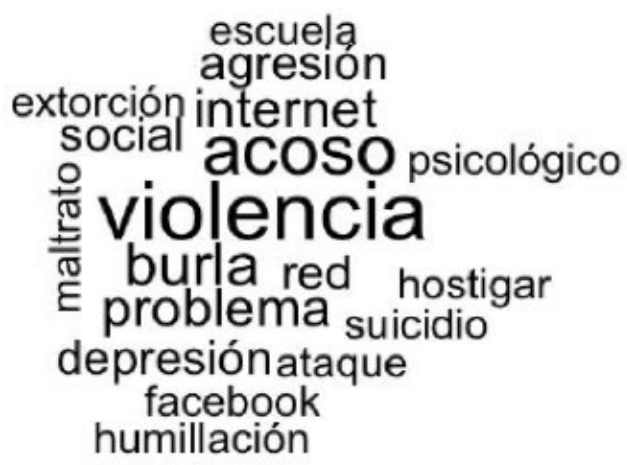

Como se puede apreciar, la palabra más destacada que surge de la mente de los universitarios cuando se habla del cyberbullying es "violencia", misma que se asocia a "acoso", "burla", "problema", "Internet", "agresión", "escuela", "extorsión", "social", "psicológico", "maltrato", "problema”, "hostigar", "suicidio", "depresión", "ataque", "Facebook" y "humillación". Por lo tanto, la representación social predominante del cyberbullying es "violencia" y "acoso".

Fuente: Elaboración propia.

Figura 2. Árbol de similitud 1.

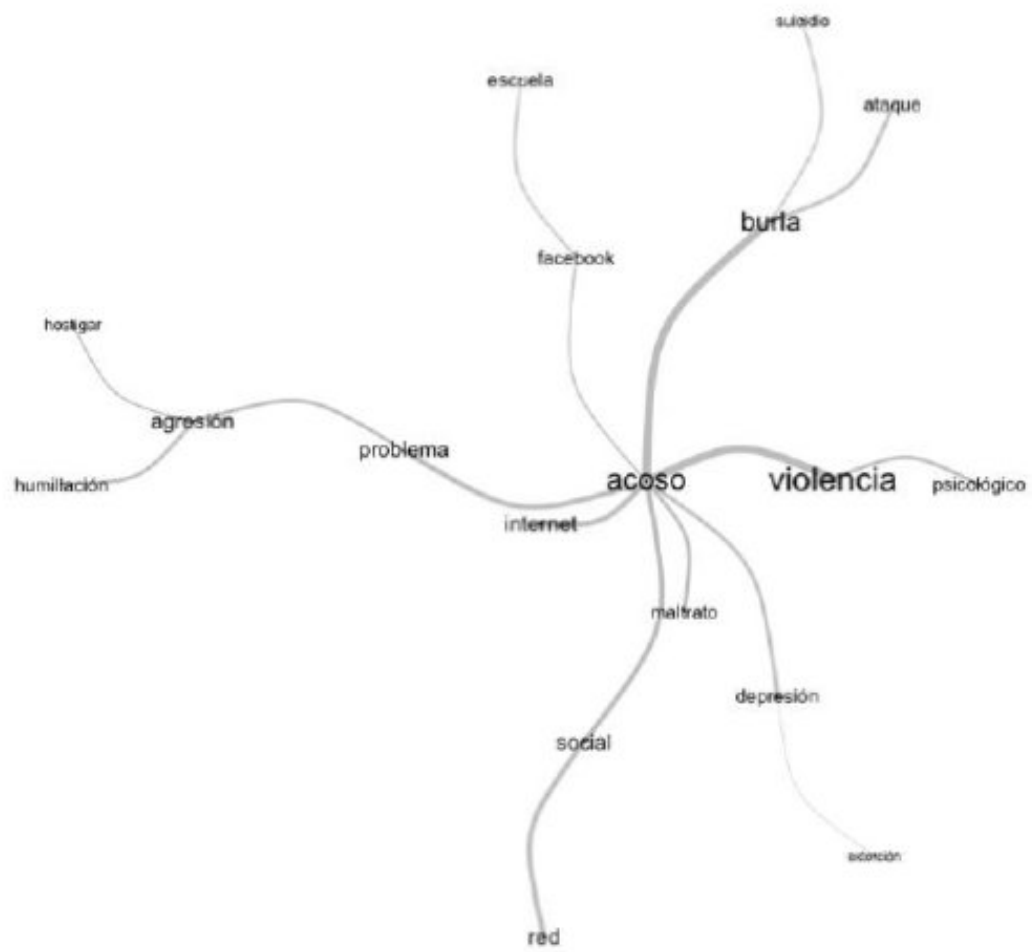

Fuente: Elaboración propia. 
Enseguida, se presenta el árbol de similitud (Figura 2), que se desprende de la palabra evocada (cyberbullying), donde se observan las relaciones y significancias con otras palabras.

Se observa que cyberbullying, para los estudiantes de la Facultad de Pedagogía, es "acoso". Sin embargo, se relaciona con las palabras "violencia", "psicológico", "burla", "ataque" y "suicidio". Una siguiente relación es "acoso" con "Facebook" y "escuela"; con "Internet"; con "problema", "agresión", "hostigar" y "humillación". Evidentemente, el acoso se articula al "maltrato"; a "red social", "depresión" y "extorsión", que los estudiantes experimentan en la escuela o universidad. Así, los efectos del cyberbullying son la depresión, el daño psicológico e, incluso, el suicidio.

Otro nivel de análisis de las representaciones sociales fue el dibujo 0 el soporte gráfico (figuras 3-12), donde destacan imágenes de Facebook, caras tristes, manos que indican desagrado, un joven tirado en el suelo con un celular en la mano, una foto rota de una pareja y un moño negro, que indica la muerte. También destacaron las palabras "angustia", "ira", "miedo" y "depresión". De manera particular, la representación sobre el cyberbullying "es un acto violento que surge por el uso inadecuado de las redes sociales y del teléfono celular, así como de la plataforma de Facebook, donde se generan afectaciones graves".

\section{Figura 3. Dibujo realizado por el Informante 1.}

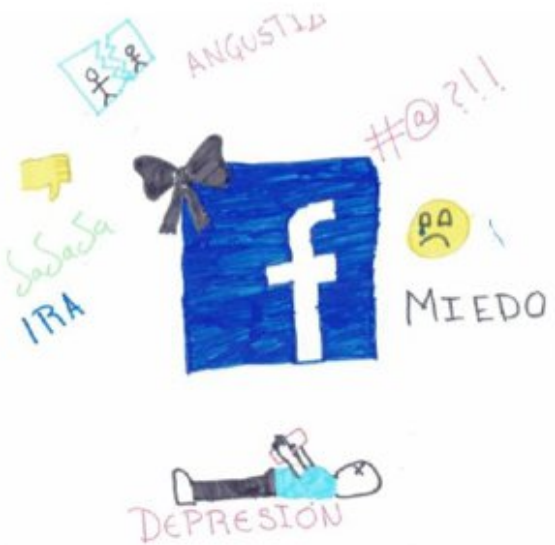

Fuente: Informante (1-Fem, 20-FP-6 ${ }^{\circ}$.

La explicación otorgada fue "el Facebook es una de las principales redes sociales en la actualidad y en donde más se han presentado casos de cyberbullying, generando depresión, ansiedad entre jóvenes y niños, algunos llegando al grado del suicidio" [sic]. 


\section{Figura 4. Dibujo realizado por el Informante 2.}

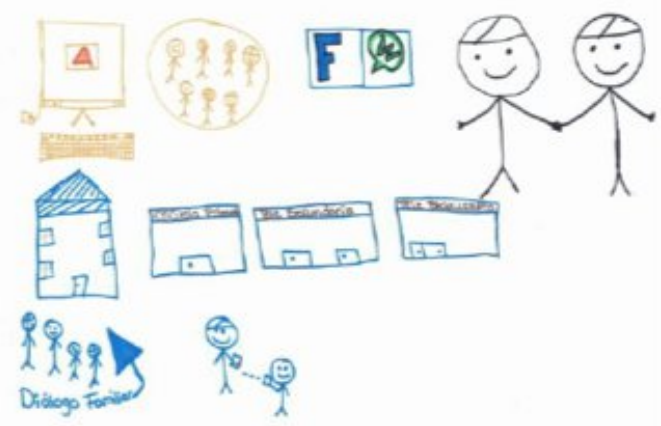

Fuente: Informante (2-Masc, 21-FP-6 ${ }^{\circ}$ ).

El informante explicó su dibujo:

lo básico para que haya cyberbullying: se necesita de una computadora (cualquier tecnología de esta) y una persona frente a ella. Detrás de eso están todos los valores y la sociedad, por tal motivo, dibujé algunas redes sociales, asi como unos chavos de la mano que simbolizan el respeto, la casa, la privacidad, que debe de existir en cada momento; el diálogo familiar ante la diversidad, los niveles educativos, porque son donde actualmente se encuentran situaciones de estas [sic].

El informante de la Figura 5 planteó:

dibujé lo anterior porque, al escuchar la palabra cyberbullying, lo relaciono con la red de Internet; por lo cual, también lo relaciono con redes sociales, co-

\section{Figura 5. Dibujo realizado por el Informante 3.}

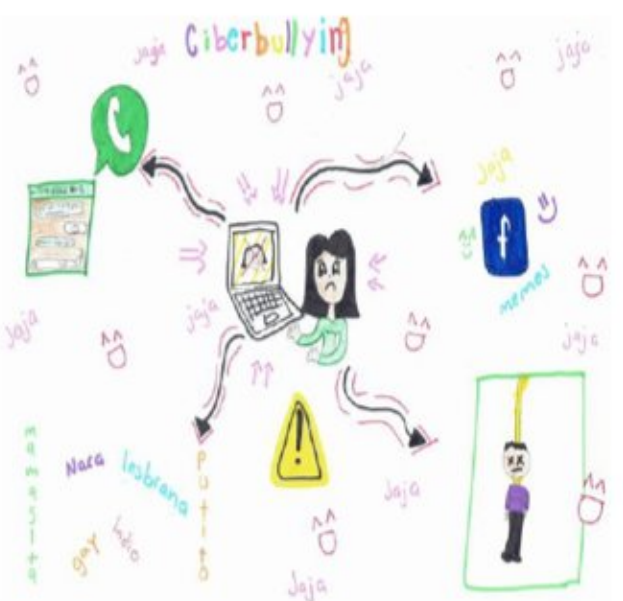

Fuente: Informante (3-Fem, 21-FP-6 ${ }^{\circ}$ ).

mo lo son Facebook, WhatsApp, donde se comparten memes, videos y fotos, que son degradantes para las personas, ofensivas, etc. Pongo un dibujo de un sujeto ahorcado, lo cual quiere decir que pueden acercar a las personas al suicidio. Pongo algunas palabras que he identificado y un signo de advertencia, porque es algo que denota ;cuidado!, es decir, que algo está mal [sic].

El estudiante explicó:

los elementos dibujados son, a mi parecer, factores que influyen para la manifestación del cyberbullying: redes sociales, dispositivos electrónicos, entre muchos otros. Sin embargo, pienso que es la falta de valores lo que da origen, y el hecho también de que no exista una sanción para ello. 
Figura 6. Dibujo realizado por el Informante 4.

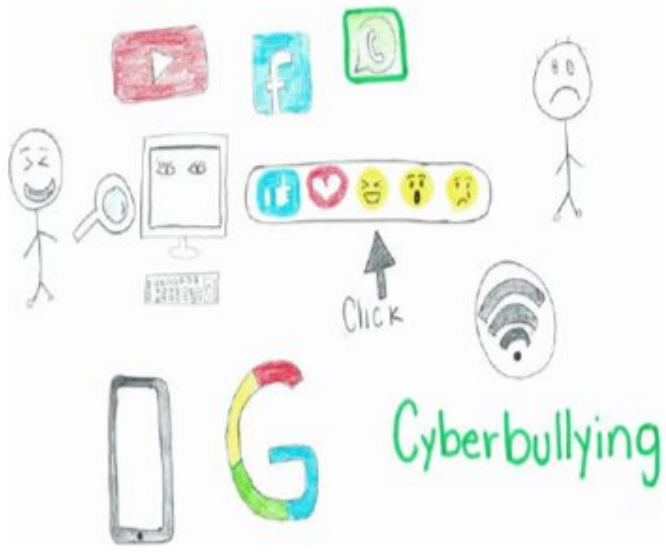

Fuente: Informante (4-Fem, 25-FP-6 ${ }^{\circ}$ ).

Figura 7. Dibujo realizado por el Informante 5.

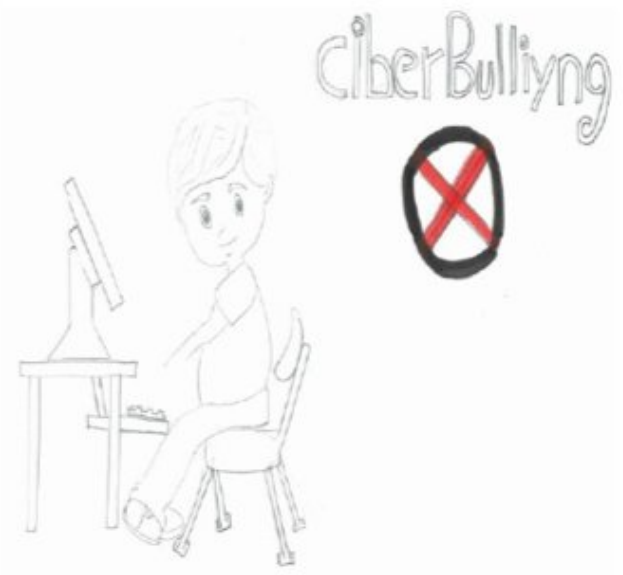

Fuente: Informante (5-Masc, 28-FP-6 ${ }^{\circ}$.

Este informante planteó:

se realizó un dibujo que para mi es un ejemplo de la situación actual de los niños, niñas, jóvenes y adultos, los cuales pasan la mayoría de su tiempo en las redes sociales; además, se representa con una $x$ la protesta a no seguir produciendo el cyberbullying [sic].
Figura 8. Dibujo realizado por el Informante 6.
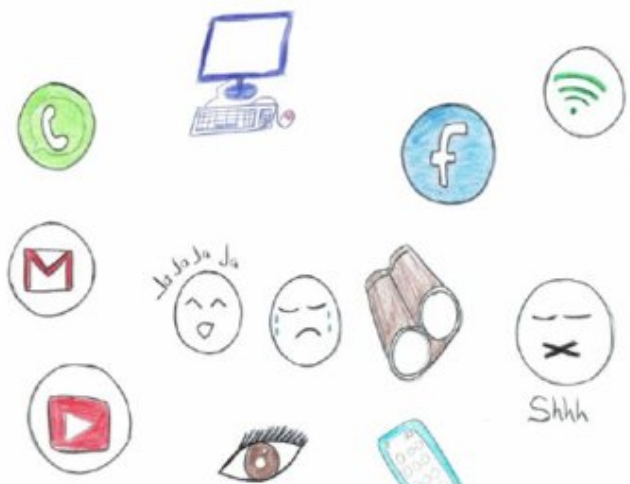

Fuente: Informante (6-Fem, 295FP-8).

El autor de la figura anterior dijo:

mis dibujos representan la conectividad, un monitor y un celular que son los instrumentos principales que utilizan los victimarios para agredir por medio de las redes sociales, como son $\mathrm{Fa}$ cebook, WhatsApp, YouTube. Dibujé los binoculares porque en las redes sociales todos somos vulnerables a ser observados, y que con ello se pueda hacer cyberbullying. Las caritas representan al agresor (la carita sonriente), que disfruta de molestar, hostigar a los demás; la carita triste representa a la víctima, quien sufre. El ojo es la persona que observa las agresiones y calla (cara con el tachecito) $[\mathrm{sic}]$. 
Figura 9. Dibujo realizado por el Informante 7.

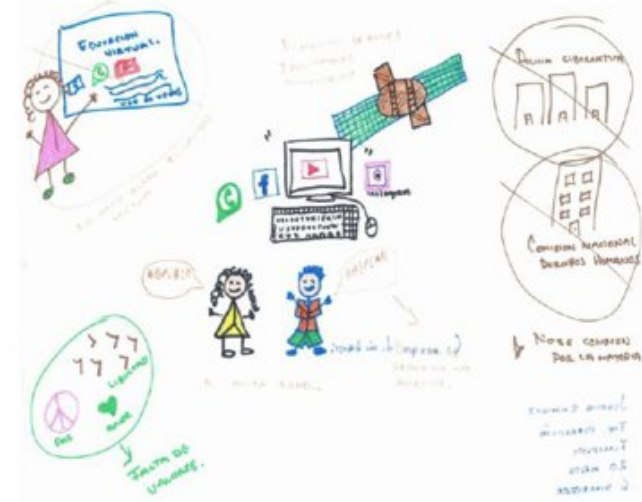

Fuente: Informante (7-Fem, 25-FP-6 ${ }^{\circ}$.

El informante de la Figura 9 explicó:

intenté reflejar el uso actual y la disposición excesiva de redes de Internet $y$ aplicaciones tecnológicas que tenemos y tienen los niños a corta edad. Todo esto da paso al cyberbullying, porque sirven como canal de difusión para hacer el mal; al igual, la falta de educación virtual y explicación de valores que son escasas y dan seguimiento a esta problemática. En el interior del dibujo aparecen las siguientes expresiones: Educación virtual-no existe mucha educación virtual; libertad, paz, amor-falta de valores; a corta edad...; dicen de groserías, más accesible; disposición de redes y aplicaciones tecnológicas; policía cibernética; Comisión Nacional de Derechos Humanos; no se conocen por la mayoría [sic].
Figura 10. Dibujo realizado por el Informante 8.

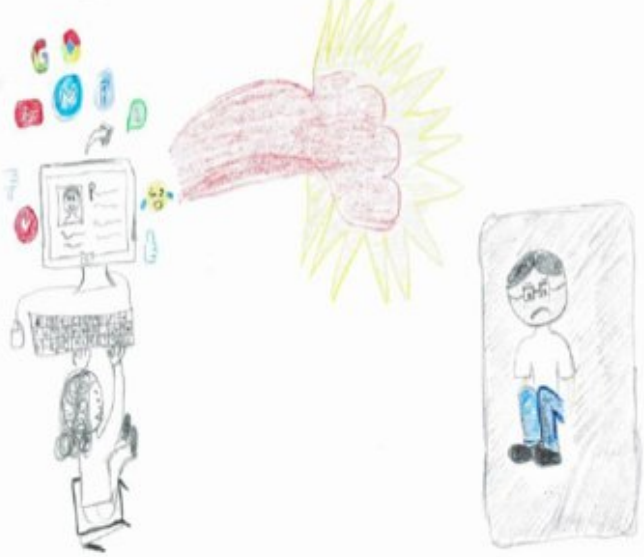

Fuente: Informante (8-Fem, 32-FP-6 ${ }^{\circ}$.

El autor de la Figura 10 comentó: "decidi dibujar esto porque represento, a través de un aparato electrónico con acceso a Internet, que su uso no es adecuado, pues hay quienes lo ocupan para agredir a otros con el afán de hacerlos sentir mal y perjudicarlos psicológicamente".

Figura 11. Dibujo realizado por el Informante 9.

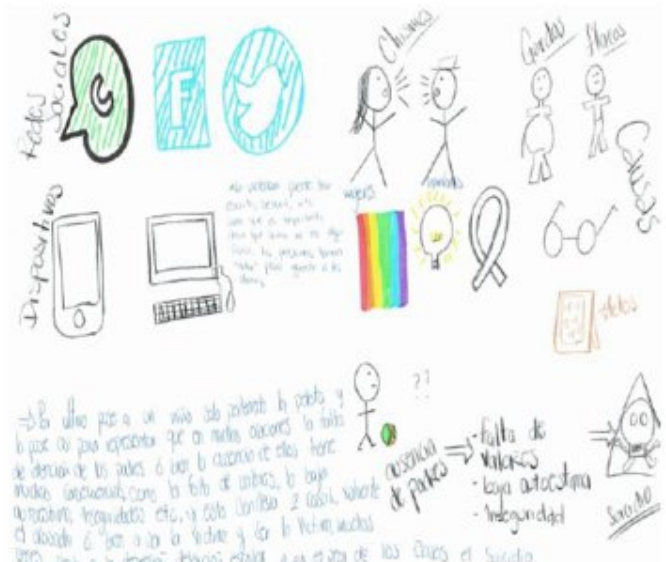

Fuente: Informante (9-Masc, 23-FP-4 ${ }^{\circ}$ ). 
Este informante expresó:

en mis dibujos, las redes sociales son las principales formas de hacer cyberbullying, como Facebook, WhatsApp, Twitter, YouTube, Instagram, etc., a través de dispositivos como smartphones o computadoras. Hay un hombre hablando a una mujer; mi intención es reconocer que hombres y mujeres hacen y son victimas de cyberbullying por igual. Las causas por las que se puede sufrir acoso: rasgos físicos, como estar gordo o flaco; alto o chaparro; usar lentes (cuatro ojos); usar ropa de marca causa discriminación. Puse también el moño, porque interpreta mucho el cáncer, el sida, o bien, el género; y creo que el hecho de tener una enfermedad también es una causa importante, sobre todo aquellos que tienen sida o sufren de alguna 'incapacidad'. Puse la bandera gay porque ellos también sufren bullying por sus preferencias sexuales; y las redes sociales son una fuente indispensable en donde hay mayor discriminación. Puse un foco porque, incluso los más inteligentes o preparados, sufren de cyberbullying en algún momento, por el simple hecho de ser responsables: nerd o ñoño. Puse un portarretrato, en el cual describo que las fotos son las principales causas de cyberbullying; fotos 'graciosas' de perso- nas que están siendo ridiculizadas o de personas desnudas o en ropa interior, que son difundidas para denigrar la integridad de la gente. También se hacen memes o videos que se difunden para perjudicar a otras personas. Un niño pateando la pelota y por la falta de atención de los padres y su ausencia tiene muchas consecuencias. Hay falta de valores, la baja autoestima, inseguridades, etc., y esto conlleva dos cosas, volverte autoestima o bien ser la víctima; y ser la víctima, muchas veces, lleva a la depresión, deserción escolar y, en el peor de los casos, al suicidio [sic].

Es importante destacar que en el interior del dibujo aparecen las siguientes expresiones: "ausencia de padres: falta de valores, baja autoestima, inseguridad", "dispositivos", "redes sociales", "chismes", "gordos", "flacos", "causas", "fotos", "mujeres", "hombres”, "suicidio", "Ia violencia puede ser sexual, etc. Creo que es importante decir que, como no es algo físico, las personas toman valor para agredir a los demás". 
Figura 12. Dibujo realizado por el Informante 10.

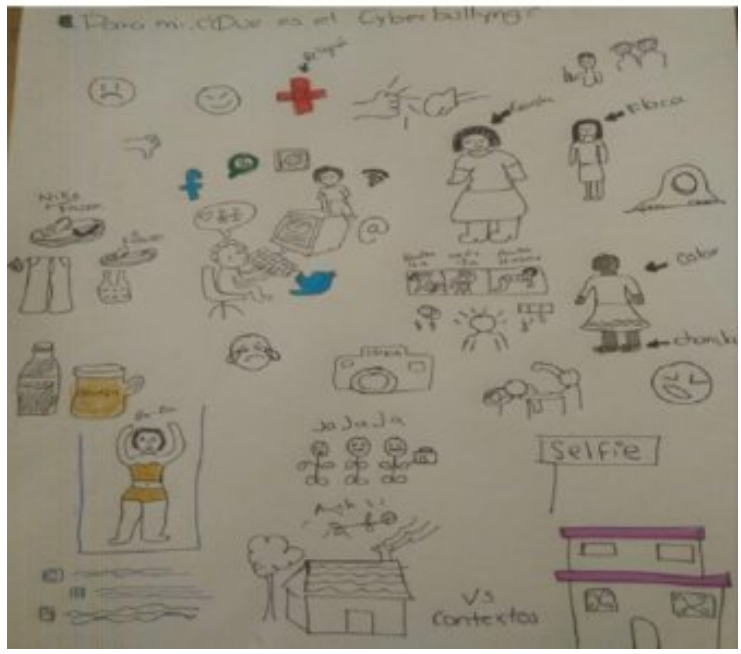

Fuente: Informante (10-Fem, 23-FP-4').

El autor de la Figura 12 planteó:

el cyberbullying, para mí, es atacar, no encajar o por seguir estereotipos. Se entiende desde la víctima y el agresor. En la computadora, Internet y redes sociales está engatusando y engañando a alguien más, que está atrás de la pantalla, con un perfil falso, siendo un hombre viejo, sin escrúpulos y con intención de dañar. La chica gorda o muy flaca, de 'color', etnia, por usar huaraches. Hay sujetos; observan imágenes de niñas menores de edad, listos con efectivo para pagar y hacer maldad, por usar ropa de marca o carísima, al lado de usar ropa cómoda, barata, o clon. El alcohol juega un papel en el cyberbullying. El mal uso y no controlarlo o no saber divertirse sin él lleva como resultado fotos que después son utili- zadas como burla. Te fotografian $y$ se burlan en vez de ayudar. La carita del abusivo, grosero, sin valores, que disfruta hacerlo. La carita triste de quien lo vive y asi se siente. La cruz por ser de distinta religión. El guante es porque el cyberbullying es un golpe. Los íconos de las redes sociales donde abunda este fenómeno. La cámara está al día con lo que sucede, y el mal se le da en capturar [sic].

El resultado de las descripciones o el corpus derivado de la explicación de cada dibujo se sometió al software IRaMuTeQ, obteniendo una nube de palabras (Figura 13) que se pueden interpretar cuando se habla de cyberbullying.

\section{Figura 13. Nube de palabras 2.}

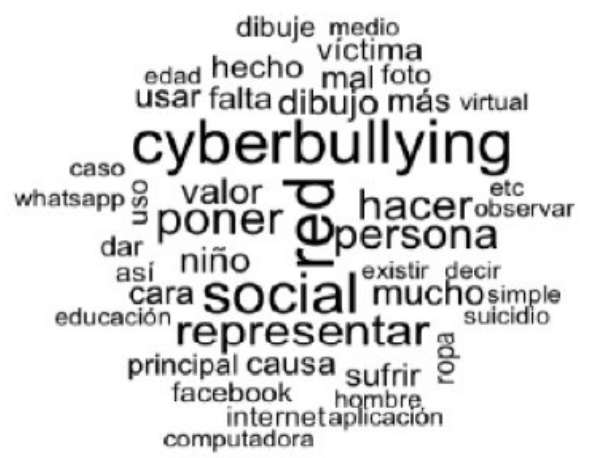

Fuente: Elaboración propia. 
Después de plasmar los dibujos, el cyberbullying representa: "red", "social", "representar", "persona", "hacer", "observar", "niño", "poner", "principal", "causa", "Facebook", "Internet", "aplicación", "computadora", "educación", "dar", "así", "WhatsApp", "mucho", "simple", "suicidio", "dibujo", "falta", "usar", "más", "virtual", "víctima", "medio", "dibujé", "ropa", "hombre", "aplicación", "causa" y "existir". Lo anterior da cuenta de que la representación social del cyberbullying es sufrir por lo que se sube a la red social.
Se observa que el cyberbullying es asociado por los estudiantes de la Facultad de Pedagogía SEA de la UV con "valor", "persona", "red", "social" e "Internet" (Figura 14).

\section{CONCLUSIONES}

Se descubrió, a partir de dos técnicas de investigación (el dibujo y la asociación de palabras libres), que el cyberbullying se ejerce por medio de la computadora, teléfono celular, dispositivo móvil o aparato electrónico con conectividad a Internet, a través de las plataformas predomi-

Figura 14. Árbol de similitud 2.

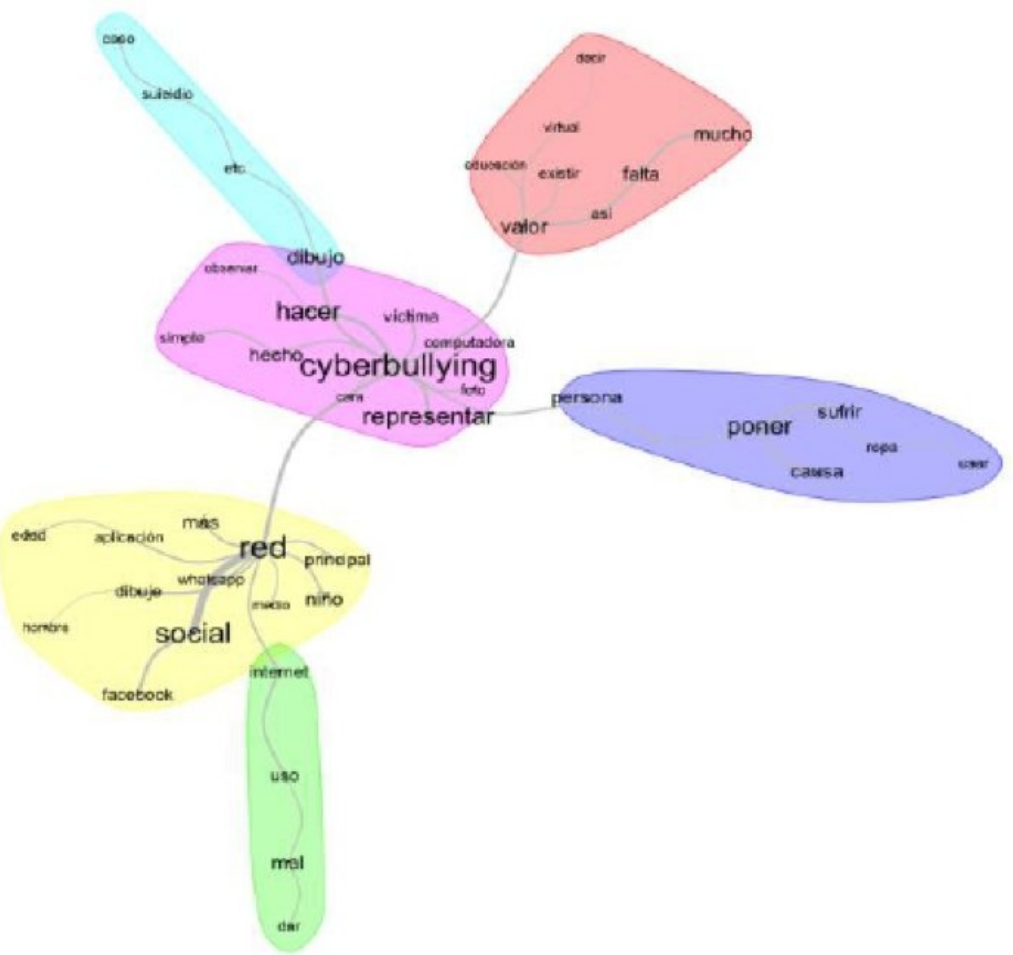

Fuente: Informante (9-Fem, 21-FP-6 ${ }^{\circ}$. 
nantes (Facebook, WhatsApp, Twitter, Instagram), conocidas como redes sociales. Los estudiantes manifestaron sentirse vulnerables y observados en estas redes, espacio virtual que se emplea para agredir, hacer sentir mal, perjudicar psicológicamente, acosar y discriminar por los rasgos físicos, o por el tipo de ropa que usan. Señalaron un estado de inseguridad en las redes sociales debido a que cualquiera tiene el valor de agredir a los demás, subir fotos denigrantes y ofensivas, videos, memes. Por lo general, quien violenta en las redes sociales lo hace de manera oculta, sin dar la cara, y la persona agredida, a pesar de que recibe agresiones, calla.

Asimismo, perciben que las afectaciones del cyberbullying son baja autoestima, depresión, deserción escolar y suicidio. Además, consideran que es necesario conocer a la policía cibernética y a la Comisión Nacional de Derechos Humanos; dialogar con las familias sobre la diversidad. Esto debe permear en los diferentes niveles educativos.
Entre las recomendaciones para evitar el cyberbullying en la universidad, se encuentran las siguientes:

1. No publicar fotos.

2. Tener control en las redes sociales.

3. No entrometerse.

4. Respeto a todas las personas.

5. Tener cuidado con lo que publicas.

6. No reenviar lo que llega.

7. Tomar conciencia sobre los peligros en las redes sociales, como la extorsión, las amenazas y el acoso.

Finalmente, los estudiantes de la Facultad de Pedagogía SEA, de la UV, también dieron cuenta de una carencia de "educación virtual" y de una "falta de valores", pues se presentan faltas de respeto y se rompe la privacidad en las redes sociales. En este sentido, debemos redoblar los esfuerzos por concientizar y brindar una cultura del buen uso de las redes sociales, plataformas e Internet. Todo esto puede emprenderse desde las aulas de la universidad. Por ello, los maestros y autoridades debemos comprometernos a informar a los estudiantes sobre los peligros que acechan a hombres y mujeres, por igual, en 
las redes sociales, y sobre las afectaciones presentes y futuras que puede generar una simple publicación.

\section{BIBLIOGRAFÍA}

Abric, J. C. (1994). Prácticas sociales y representaciones. México: Coyoacán.

Banchs, M. A. (2000). Aproximaciones procesuales y estructurales al estudio de las representaciones sociales. Venezuela: Universidad Central de Venezuela.

Castro, A. (2012). Conflictos en la escuela de la era digital. Tecnología y violencia. Buenos Aires, Argentina: Bonum.

Casillas, M. A., Ramírez, A., y Ortiz, V. (2014). El capital tecnológico, una nueva especie de capital cultural. Una propuesta para su medición. En A. Ramírez y M. A. Casillas, Háblame de TIC: tecnología digital en la educación superior (pp. 23-38). Córdoba, Argentina: Brujas.

Dorantes, J. J. (2016). Redes sociales y el ciberbullying en la Universidad Veracruzana. Revista Ensayos Pedagógicos. Edición Especial, 169188. Recuperado de http://www.revistas.una.ac.cr/index.php/ensayospedagogicos/article/view/9346/11086
Dorantes, J. J. (2017). Las

representaciones sociales de los estudiantes sobre la violencia. Caso Universidad Veracruzana. En M. E. Ruiz Libreros (Coord.), Complejidad, innovación y sustentabilidad. Experiencias educativas (pp. 163179). Xalapa, Veracruz, México: Códice, Universidad Veracruzana.

Dorantes, J. J., Oliva, L., y Rivera, E. (agosto, 2017). El ciberbullying en jóvenes universitarios, casos y afectaciones. Ponencia presentada en el III Congreso Internacional de Transformación Educativa: Perspectiva y emancipación social por una educación creadora. Veracruz, México.

Dorantes, J. J., Lagunes, Y. I., Oliva, L., y Rivera, E. A. (2019). Maestros en acción ante el cyberbullying en la escuela. Xalapa, Veracruz, México: Imaginarial. Recuperado de https://www.uv.mx/personal/jedorant es/files/2019/03/Editorial-RequeridaMaestros-en-accion-ante-elcyberbullying-en-la-escuela.pdf

Flament, C. (1994). Estructura, dinámica y transformación de las representaciones sociales. En J. C. Abric (Coord.), Prácticas de las Representaciones Sociales. México: Coyoacán.

Furlán, A., Pasillas, V. M. A., Spitzer, T. C., y Gómez, N. A. (Coords.). (2010). Violencia en los centros educativos. Conceptos, diagnósticos e intervenciones. Argentina: Noveduc Libros del Centro de Publicaciones Educativas y Material Didáctico S. R. L. 
Junta de Castilla y León. (2010).

Manual del buen uso de los medios

informáticos. España: Autor.

Leoni, S. (enero-marzo, 2012).

Sobreviviendo en el ciberespacio.

Contribuciones a las Ciencias

Sociales, (15). Recuperado de

http://www.eumed.net/rev/cccss/19/sl

.html

Molina-Neira, J. (2017). Tutorial para el análisis de textos con el software

IRaMuTeQ. Barcelona, España:

Grupo de Investigación DHIGES, Universidad de Barcelona.

Recuperado de

https://www.researchgate.net/publica tion/315696508_Tutorial_para_el_an alisis_de_textos_con_el_software_IR AMUTEQ

Molina, J. A., y Vecina, P. (2015).

Bullying, ciberbullying y sexting.

¿Cómo actuar ante una situación de acoso? España: Pirámide.

Morales, R. T., Serrano, B. C., Miranda,

G. D. A., y Santos, L. A. (2014).

Ciberbullying, acoso cibernético y

delitos invisibles. Experiencias

psicopedagógicas. México:

Universidad Autónoma del Estado de

México.

Moscovici, S. (1979). El psicoanálisis, su imagen y su público. Buenos

Aires, Argentina: Huemul [Original:

Moscovici, S. (1961). La

psychanalyse, son image et son

public. France: Presses

Universitaires de France].

Ortega-Ruiz, R., y Zych, I. (2016). La ciberconducta y la psicología educativa. Psicología Educativa, 22(1), 1-4. 